\title{
ISRAEL E A ORGANIZAÇÃO PARA A LIBERTAÇÃO DA PALESTINA: COMO OCORRE A COOPERAÇÃO ECONÔMICA ENTRE DUAS NAÇÕES EM CONFLITO?
}

\author{
ISRAEL AND PALESTINE LIBERATION ORGANIZATION: HOW DOES THE \\ ECONOMIC COOPERATION OCCUR BETWEEN TWO NATIONS IN \\ CONFLICT?
}

DOI: 10.5380/cg.v9i2.73010

Maiko Jhonata De Araújo Gomes ${ }^{1}$

\begin{abstract}
Resumo
O presente trabalho tem como objetivo geral analisar como funciona a cooperação entre duas nações em conflito, sob um Sistema Internacional anárquico, com foco no caso da cooperação econômica entre Israel e a Organização para a Libertação da Palestina (OLP). Através do uso da metodologia qualitativa exploratória, a pesquisa tem como objetivos específicos: (I) expor a lógica da cooperação sob a anarquia, baseando-se, principalmente nas obras de Axelrod e Keohane (1985) e Oye (1985); e; (II) examinar especificamente o Protocolo de Paris (1994), um importante acordo econômico firmado entre as partes, com o intuito de evidenciar o objetivo geral deste trabalho. Dessa forma, a pergunta-problema pode ser caracterizada como: é possível haver uma cooperação econômica, com ganhos absolutos significativos, entre duas nações em conflito? Portanto, a hipótese é que mesmo havendo a concordância, entre duas nações em conflito, em buscar uma maior aproximação econômica, essa cooperação manifesta-se como assimétrica e sem ganhos absolutos significativos visíveis para um dos lados. Assim, conclui-se que mesmo inseridos em um Sistema Internacional anárquico, duas nações podem tanto entrar em guerra, quanto buscar a cooperação, de modo que ao optar pela cooperação, o que se observa é a existência de um jogo de quem perde menos em relação ao outro, além da acomodação do conflito, já que não há ganhos absolutos plenos para ambos os lados, mas sim ganhos relativos.
\end{abstract}

Palavras-Chave: Cooperação econômica; Conflito palestino-israelense; Sistema Internacional anárquico.

\begin{abstract}
The present work has as general objective to analyze how the cooperation between two nations in conflict works, under an anarchic International System, with focus on the economic cooperation between Israel and Palestine Liberation Organization (PLO). Through the use of qualitative exploratory methodology, the research has as specific objectives: (I) to expose the logic of cooperation under anarchy, based mainly on the works of Axelrod and Keohane (1985) and Oye (1985), and; (II) specifically to examine the Paris Protocol (1994), an important economic agreement signed between the parties, in order to highlight the general objective of this work. Thus, the problem-question can be characterized as: is it possible to have economic cooperation, with significant absolute gains, between two nations in conflict? Therefore, the hypothesis is that even if there is an agreement, between two conflicting nations, to seek greater economic approximation, this cooperation is manifested as asymmetrical and with no significant absolute gains visible to one side. Thus, it is concluded that even inserted in an anarchic International System, two nations can either go to war or seek cooperation, so that when opting for cooperation, what is observed is the existence of a game of those who lose less in relation to the other, in addition to settling the conflict, since there are no full absolute gains for both sides, but relative gains.
\end{abstract}

Keywords: Economic cooperation; Palestinian-Israeli conflict; Anarchic International System.

${ }^{1}$ Mestrando em Relações Internacionais pelo Programa de Pós Graduação em Relações Internacionais da Universidade Estadual da Paraíba (PPGRI-UEPB). E-mail: maikojhonata@hotmail.com. ORCID: https://orcid.org/0000-0002-0110-6750. 


\section{INTRODUÇÃO}

Com o objetivo de dividir o território da Palestina histórica ${ }^{2}$ em um Estado árabe e outro judaico, é criada a Comissão Especial das Nações Unidas para a Palestina (UNSCOP) em 1947³. O plano de partilha final, de 1948, não agradou nenhum dos lados envolvidos, principalmente o lado árabe, que era maioria numérica e tinha um longo passado histórico e cultural na região. Logo após o Plano de Partilha ter sido colocado em prática, estoura a Guerra Árabe-Israelense (1948-1949). O conflito, que ficou conhecido como Guerra da Independência para os judeus e como "A catástrofe" para os árabes, termina com a vitória israelense, que ocupa boa parte do território que seria destinado ao Estado árabe (GOMES, 2001, p. 82-93; PILATI; PIRES, 2008, p. 12-13).

Como consequência, a nação palestina não conseguiu se consolidar como um Estado plenamente efetivo e reconhecido. Assim, desde 1948, palestinos e nações aliadas do mundo árabe enfrentaram Israel em diversos conflitos e guerras específicas dentro deste intermédio de tempo, como: a Guerra do Suez, também conhecida como Segunda Guerra Árabe-Israelense (1956); a Guerra dos Seis Dias (1967), e; a Guerra do Yom Kippur (1973). Ademais, ocorrem ainda a Primeira (1987-1993) e Segunda (2000) Intifadas. Ambas representavam manifestações da população palestina contra o status quo político e econômico nos Territórios Palestinos Ocupados (TPO), onde ocorreram ondas de violência, protestos e ação direta contra os militares israelenses (KURBAN, 2017, p. 51; SILVA, 2012, p. 136).

É válido destacar aqui que o termo TPO diz respeito à dimensão geográfica dos territórios originalmente atribuídos ao povo palestino, que têm sido continuamente ocupados militarmente e indevidamente, por Israel, desde 1948. Já a OLP, criada em 1964, é a entidade máxima de representação do povo palestino e seria a base para uma futura entidade palestina, além de ser, também, a representante do povo palestino nas Conferências da Liga Árabe4 (LOPES, 2007, p. 7677). Por sua vez, a Autoridade Nacional Palestina (ANP) surge como consequência do Acordo de Oslo I, em 1993, e representa um órgão provisório de autogoverno dos territórios palestinos.

\footnotetext{
2 Palestina neste contexto diz respeito ao antigo nome dado à região, até 1947, que hoje diz respeito à Israel e Territórios Palestinos Ocupados.

3 É válido destacar que a necessidade de constituir um Estado palestino e um israelense, através da UNSCOP, ocorre devido à um longo conflito que já perdurava há décadas. Apesar de que já haviam discordância e conflitos na região, a situação se agrava a partir de 1922, com a instauração do mandato britânico sobre a região da Palestina histórica. Em princípio, o Reino Unido deveria administrar a região até que dois Estados pudessem se estruturar devidamente para, assim, tornaram-se independentes. Contudo, houve uma priorização ao povo judeu, devido à um comprometimento já antigo do Reino Unido de estabelecer uma nação judaica na região, visto que os judeus apresentavam grande relevância e influência dentro dos principais governos, bancos e empresas daquele período, em diversos países da Europa. Como consequência, os árabes palestinos passaram a adotar medidas de revolta e oposição ao mandato britânico, como desobediência civil, recusa de pagamento de impostos e manifestações armadas. As revoltas tornaram-se ainda mais frequentes com o aumento considerável de imigração judaica para a região, como consequência das mudanças políticas na Alemanha (PACTO DA SOCIEDADE DAS NAÇÕES, 1919, art. 22; SOARES, 1989; GRESH, 2002, p. 12-16; GOMES, 2016, p. 128).

4 A nação palestina, sob representação da OLP, é um dos Estados-membros da Liga Árabe, desde 1976.
} 
Dado o exposto, o presente trabalho busca compreender a cooperação econômica entre Israel e Organização para a Libertação da Palestina (OLP), visto que as duas partes estão em conflitos há décadas. Portanto, o problema de pesquisa deste trabalho pode ser avaliado sendo como: toda cooperação econômica traz de fato resultados igualmente benéficos para ambas as partes?

Além disso, faz-se uso da metodologia qualitativa exploratória, pois a mesma possibilita que o tema aqui abordado seja aprofundado e bibliografia seja levantada, de modo a familiarizar leitores e/ou outros pesquisadores com esta temática. Ademais, faz-se uso de um arcabouço teórico e histórico, sendo utilizadas como fontes de pesquisa: livros, acordos internacionais e artigos. Portanto, a pesquisa busca: (I) expor a lógica da cooperação sob a anarquia, baseando-se, principalmente nas obras de Axelrod e Keohane (1985) e Oye (1985), e; (II) examinar especificamente o Protocolo de Paris (1994), um importante acordo econômico firmado entre as partes, com o intuito de evidenciar o objetivo geral.

A hipótese aqui observada é que a necessidade de desenvolver e firmar um acordo econômico tão importante como este, segue uma agenda política e econômica específica do lado dominante, ou seja, Israel. Dessa forma, observa-se que mesmo em um cenário de cooperação, a assimetria de poderes é tamanha, ao ponto de continuar a perpetuação da dependência econômica evidente há décadas.

Desta maneira, para melhor apresentar e problematizar essa hipótese, o presente trabalho aborda primeiramente a fundamentação teórica para esta pesquisa, no caso, o neoliberalismo institucional de Axelrod e Keohane (1985), Oye (1985) e Grieco (1988), principalmente. Desta maneira, para esta perspectiva, mesmo existindo em um Sistema Internacional anárquico, os Estados buscam firmar cooperações, com o intuito de reduzir os efeitos da anarquia e maximizar seus ganhos absolutos.

Já o segundo tópico irá adentrar no que é, de fato, o propósito do texto: a cooperação econômica entre Israel e OLP. Dessa forma, será apresentado primeiramente como funcionava a relação econômica entre as duas partes de 1967 a 1993. Em seguida, será analisado o Protocolo de Paris (1994), um dos principais acordos econômicos assinado entre as partes até a atualidade. O tópico finaliza a discussão ao expor como este acordo impactou as relações entre os dois lados, de maneira assimétrica e desproporcional.

\section{COOPERAÇÃO INTERNACIONAL ENTRE ESTADOS EM GUERRA}

Para dar início a este trabalho, é necessário expor a fundamentação teórica que vai embasar toda a pesquisa. Assim, será exposto nesta primeira seção, a lógica da cooperação no Sistema Internacional anárquico e como ela acontece mesmo entre Estados inimigos ou em guerra. 
Segundo o neoliberalismo institucional de Axelrod e Keohane, pelo fato de não existir um governo supranacional no Sistema Internacional, a cooperação entre Estados é difícil de ser alcançada, visto que pelos padrões das sociedades domésticas, as instituições internacionais desempenham um papel fraco, enquanto que a trapaça e desilusão são endêmicos nas relações internacionais. Todavia, os autores destacam que o Sistema não representa um estado de guerra homogêneo, podendo variar de acordo com os problemas ao longo do tempo (AXELROD; KEOHANE, 1985, p. 226).

Dessa forma, pelo fato de os Estados serem atores racionais, eles preferem a cooperação, pois a mesma possibilita que todos os lados envolvidos maximizem seus ganhos absolutos individuais, ou seja, independentemente de quanto cada parte ganhará, todos irão ganhar. Assim, os Estados são caracterizados como "egoístas", pois são indiferentes para os ganhos conquistados por outros (GRIECO, 1988, p. 487-496).

Destarte, os autores destacam que a cooperação não é equivalente a harmonia, visto que a harmonia exige interesses perfeitamente mútuos, enquanto a cooperação ocorre em situações que contenham não só interesses complementares, mas também conflitantes. Em outras palavras, os atores devem estar dispostos a ajustar seus comportamentos às preferências reais ou antecipadas dos outros para que a cooperação possa ocorrer devidamente (AXELROD; KEOHANE, 1985, p. 226). Essa lógica exposta por Axelrod e Keohane (1985), de que em uma cooperação ambas as partes devem estar dispostas a ajustar seus comportamentos, diz respeito, principalmente, à estrutura de pagamentos. Isso significa que, dentro dessa estrutura social, os atores vão se beneficiar nessa relação.

De maneira semelhante, Oye (1985) afirma que estrutura de pagamentos serve como uma variável interveniente entre a cooperação internacional e os fatores estruturais cognitivos, domésticos e internacionais. Assim, ao relacionar a cooperação com a lógica de ajuste de comportamentos e estrutura de pagamentos, pode-se dizer que a cooperação é desejável, mas não automática. Nesses casos, a capacidade dos Estados de cooperar em um cenário de ausência de um poder supranacional, é vital para a realização de um bem comum (OYE, 1985, p. 5-6).

É importante frisar que existe ordem mesmo em um cenário de anarquia e que cooperações podem existir num Sistema Internacional anárquico, visto que a ausência de um governo superior comum permanece uma constante, independentemente dos acontecimentos. Mas, ocorre uma variação no grau em que as interações são estruturadas e nos meios pelos quais elas são estruturadas (AXELROD; KEOHANE, 1985, p. 226).

Segundo Barnathan (2006, p. 265), neoliberais assumem que as interações são mútuas e simétricas, ou que a assimetria não é crucial. Todavia, os ganhos esperados em trocas comerciais serão bem diferentes em relações com grandes disparidades de poder econômico entre os dois Estados, de modo que, em boa parte das situações, o Estado economicamente mais forte tende a ter ganhos maiores. 
Essa divergência de poderes e nos ganhos esperados cria três problemas inter-relacionados, mas diferentes: (I) o problema do poder coercivo: as relações comerciais assimétricas acumulam benefícios políticos para o Estado maior, conferindo-lhe poder coercivo sobre o Estado mais fraco; (II) o problema do efeito de influência: o Estado mais poderoso projeta poder sobre o Estado mais fraco, de modo a influenciá-lo; (III) o problema da concordância: é provável que o Estado mais fraco mude sua percepção de seus próprios interesses e convirja para os do Estado mais forte, porque as relações comerciais provavelmente levarão a novos interesses (BARNATHAN, 2006, p. 265).

Liberman (1996) aprofunda a discussão ao focar nas trocas comerciais entre Estados inimigos. Segundo o autor, a riqueza é uma importante fonte de influência e é a principal fonte de capacidade militar, assim, a cooperação que possui a capacidade de distribuir riqueza afeta diretamente a segurança e o bem-estar do Estado. Dessa forma, os Estados devem levar em consideração, igualmente, as implicações de segurança da cooperação ao lado de seus benefícios na política econômica externa (LIBERMAN, 1996, p. 147).

Para o autor, de modo semelhante à Axelrod \& Keohane e Oye, a estrutura do sistema pode determinar de modo significativo a sensibilidade dos ganhos relativos (em uma cooperação, os Estados preocupam-se mais em quanto eles vão ganhar se comparado aos outros Estados na relação, do que o ganho final propriamente dito) porque condiciona a direção e a variabilidade das ameaças. Esses aspectos da ameaça são importantes porque as rivalidades e alianças podem mudar com o tempo, especialmente sob multipolaridade (LIBERMAN, 1996, p. 153).

Pelo fato de que esses aspectos mudam constantemente em um sistema multipolar anárquico, Barbieri e Levy (1999, p. 464) apresentam uma relação mais intrínseca entre a cooperação e a possibilidade de guerra. Para eles, a possibilidade dos líderes anteciparem que um conflito seria capaz de prejudicar os ganhos alcançados previamente, através da cooperação econômica e a troca comercial, seria o suficiente para que os mesmos adotassem medidas para evitá-lo.

Contudo, caso estes líderes não sejam capazes de impedir a eclosão de um conflito, o mesmo seria capaz de acabar ou reduzir drasticamente com os ganhos alcançados no campo econômico. Neste cenário, para os neoliberais, a perda dos ganhos do comércio diz respeito não apenas às perdas sofridas durante a guerra em si, mas também na possibilidade da guerra impactar negativamente em relações comerciais futuras, pelo menos por um tempo (BARBIERI; LEVY, 1999, p. 464-465).

Seguindo a mesma lógica de Liberman, Barbieri e Levy, de que a economia pode interferir na segurança e bem-estar de um Estado, Barnathan (2006) foca na ideia de construir a paz com base na cooperação. Para a autora, a cooperação econômica é um bom ponto de partida para construir a cooperação nos mais altos e amplos níveis dos problemas políticos e de segurança, visto que a integração econômica pode trazer paz e/ou ajudar a atualizar a paz propriamente dita (BARNATHAN, 2006, p. 262).

Segundo Miller (2005, p. 231-232), a transição para a paz é um processo, com diferentes estágios que variam de acordo com o grau de estabilidade. No mais baixo nível está o estágio da “paz 
fria”, que representa uma condição em que as principais questões em conflito são mitigadas, mas não totalmente resolvidas, ou seja, há uma probabilidade da guerra ser retomada, caso ocorram mudanças internacionais ou domésticas. Assim, existe a possibilidade de haver a assinatura de um tratado de paz que põe fim ao estado formal de guerra entre os antigos beligerantes.

A “paz normal” existe quando as principais questões são resolvidas e os laços transnacionais começam a se desenvolver. Aqui, há uma menor possibilidade da guerra ser retomada. O terceiro estágio, da "paz calorosa", ocorre quando os laços transnacionais estiverem altamente desenvolvidos, os principais problemas que envolvem o conflito forem resolvidos por completos e o retorno à guerra se tornar impensável. Este nível de paz é caracterizado por relações transnacionais extensíveis, visto que, Miller compreende que existem certos arranjos cooperativos regionais que transcendem a lógica do conflito em si, como empreendimentos econômicos conjuntos, relações comerciais, instituições regionais ou trabalho conjunto em problemas comuns como o meio ambiente (MILLER, 2005, p. 231-232).

Miller (2005, p. 257-258), propõe um cenário em que um progresso gradual em direção à uma paz calorosa pode ser implementado no contexto palestino-israelense, usando as três estratégias de pacificação sucessivamente. Logo no primeiro estágio, ele propõe uma atuação dos Estados Unidos, como intermediador, para negociar um acordo para o estabelecimento de um Estado palestino, que provavelmente produziria apenas uma paz fria. A paz normal e, consequentemente, a paz calorosa somente seriam alcançadas através dessa interferência estadunidense, com apoio da OTAN (Ibidem, 2005, p. 257-258).

Contudo, a experiência de ambos os Acordos de Oslo, que contaram com a mediação dos Estados Unidos, mostra o contrário. Apesar de Miller levar em consideração que a relação entre Israel e palestinos ser assimétrica, ele não leva em consideração que a relação é, também, de dependência. Como será exposto no tópico a seguir, a dependência palestina para com Israel é um fator significativo que não deve ser excluído.

Barnathan relaciona a ideia de Miller, de alcançar a paz através da cooperação, com a lógica de disparidade de poder econômico. Para Barnathan, as amplas disparidades de poder - político e/ou econômico - criam dificuldades em todos os estágios da transição para a paz. No primeiro estágio, contudo, essas dificuldades encontradas não só são mais fáceis de serem reduzidas, como há a chance de novos incentivos para a cooperação surgirem como consequência da disparidade de poderes. $\mathrm{O}$ Estado mais poderoso pode interessar-se em usar incentivos econômicos tanto para avançar as relações políticas gerais e encorajar seu antigo inimigo a assinar um tratado de paz para acabar com as hostilidades, quanto para amenizar o impacto negativo da disparidade de poder econômico. Outra alternativa que pode ser usada para amenizar ou superar o impacto negativo de amplas disparidades de poder econômico, é o envolvimento de um terceiro Estado (BARNATHAN, 2006, p. 265-266).

Já no segundo e terceiro nível de paz, em que há uma maior relação entre as partes, o impacto negativo dessas disparidades é mais difícil de ser amenizado. Há, nestes níveis, uma maior 
preocupação com o fato de a assimetria de poder desenvolver um efeito de coerção e influência no futuro. Portanto, mesmo que os problemas iniciais sejam superados, a assimetria de poderes pode apresentar efeitos negativos de longo prazo, no período de normalização das relações. Consequentemente, o parceiro mais fraco provavelmente tentará extrair o máximo possível de benefícios econômicos de curto prazo que possa obter com a assinatura de um tratado de paz, mas adotará uma postura mais resistente para com um possível processo de normalização econômica plena que implique uma interação econômica maior e mais livre com seu antigo inimigo, que por sua vez, representa o lado mais poderoso (BARNATHAN, 2006, p. 266).

Como vai ficar mais evidente a seguir, esse raciocínio exposto por Barnathan fica muito visível nas relações comerciais entre Israel e Territórios Palestinos Ocupados (TPO). Essa assimetria de poderes é evidente pelo fato de Israel ser um Estado plenamente reconhecido internacionalmente e por receber apoio direto de grandes potências. Dessa forma, o Estado israelense possui um poder coercitivo, de modo a influenciar a tomada de decisão ou a percepção do povo palestino sobre essa relação, visto que os TPO não representam um Estado plenamente reconhecido internacionalmente e está inserido nessa lógica de dependência desde o começo do século XX.

Dado o exposto, de acordo com uma perspectiva neoliberal em Relações Internacionais, é possível que duas nações em conflito busquem uma cooperação econômica conjunta, com o intuito de alcançar a paz e estabilidade entre as partes e reduzir os danos causados pelo conflito em si. Dessa forma, no tópico a seguir será feita a exposição de como funcionava as relações econômicas e comerciais entre Israel e o povo palestino de 1967 até 1994, quando o Protocolo de Paris foi assinado com intuito de construir uma estrutura econômica estável e independente para o povo palestino e, assim, possibilitar relações comerciais mais simétricas com Israel e, consequentemente, alcançar a paz entre as partes.

\section{PROTOCOLO DE PARIS: A EFETIVAÇÃO DA COOPERAÇÃO ECONÔMICA}

A década de 1990 foi marcada por alguns acordos significativos entre o Estado de Israel e a OLP que buscavam não só a paz entre os lados, mas, também, uma abertura comercial e uma cooperação mais forte na economia, dentre eles, o Acordo de Oslo I (1993)5, Protocolo de Paris (1994)

5 A Declaração dos Princípios sobre os Arranjos Próprios do Governo Independente, também conhecida como
Acordo de Oslo I, foi assinado em outubro de 1993 e foi apresentado como um documento oficial dentro do
contexto da $48^{\text {a }}$ Assembléia Geral das Nações Unidas e do Conselho de Segurança. O principal objetivo das
negociações palestino-israelenses, naquele contexto, como expõe o Artigo I, era estabelecer uma Autoridade
Auto Governante Interina Palestina, para o povo palestino na Cisjordânia e a Faixa de Gaza, por um período
de transição não superior a cinco anos, levando a um acordo permanente. Com o fim das negociações, o
objetivo é alcançado e surge a Autoridade Nacional Palestina (ANP). Dessa forma, o acordo buscou explicitar
detalhadamente como deveria funcionar toda a estrutura burocrática, jurídica e legal dessa Autoridade (ONU,
1993, p. 4). Quase dois anos depois, em setembro de 1995, é firmado o Acordo Provisório sobre a Cisjordânia 
e Oslo II (1995). Dado o exposto, esse tópico terá como foco específico o Protocolo de Paris (1994). Todavia, é necessário, primeiramente, expor como funcionava a relação econômica entre Israel e TPO antes da assinatura do Protocolo.

Após a Guerra dos Seis Dias, em 1967, uma boa parte do território palestino foi ocupado por Israel, que forçadamente separou os TPO das relações comerciais anteriores mantidas com o restante do mundo, além de ter forçado novos laços econômicos assimétricos com Israel. O Estado de Israel permitia apenas algumas exportações palestinas para os mercados árabes com severas restrições às importações desses mercados; as áreas palestinas tornaram-se um "parceiro" de Israel em uma união aduaneira de fato e unilateral - os produtos israelenses tinham livre acesso aos mercados dos Territórios Palestinos Ocupados, enquanto os produtos palestinos estavam sujeitos a restrições regulatórias (UNCTAD, 2012, p. 10-11).

Israel impôs limitações violentas ao uso da água e da terra, cultivo de certas culturas e estabelecimento de projetos de investimento. Além disso, não havia sistema financeiro ou bancário, e os fazendeiros e fabricantes palestinos foram efetivamente excluídos das várias formas de subsídios públicos que eram concedidos aos israelenses (UNCTAD, 2012, p. 11). Segundo a organização B’Tselem (2011), Israel não só impôs tais medidas em relação à agricultura, como propositalmente buscou danificar esse setor tão importante para a economia palestina, como por exemplo, adotou medidas restritivas para a exportação de produtos agrícolas direcionados à Israel.

Questões trabalhistas também foram alteradas, um exemplo disto foi que Israel passou a incentivar a entrada em massa de palestinos no mercado de trabalho israelense, particularmente na construção, agricultura e serviços (B’TSELEM, 2011). Todavia, apesar de Israel ter adotado esse incentivo da entrada em massa de trabalhadores palestinos, esses indivíduos eram obrigados a pagar contribuições nacionais de seguro sem ter direito à maioria dos benefícios correspondentes (UNCTAD, 2012, p. 11).

Como consequência dessas imposições, em 1992, um ano antes da assinatura do Acordo de Oslo I, um terço da força de trabalho palestina estava empregada em Israel; cerca de 90\% das importações eram de origem israelense; e aproximadamente 80\% das exportações foram vendidas em Israel ou repassadas por seus portos. Este período de 27 anos de ocupação indevida e controle direto de Israel sobre os TPO, acarretou em uma economia palestina não desenvolvida, sem um setor industrial moderno e com altas taxas de desemprego e pobreza (B’TSELEM, 2011).

Seis meses após o Acordo de Oslo I, em abril de 1994, é firmado o Protocolo sobre Relações Econômicas entre o Governo do Estado de Israel e a OLP, também conhecido como Protocolo de Paris. Este protocolo, ao contrário do Acordo de Oslo I, tinha o caráter especificamente econômico, visto que, como expõe o preâmbulo, ambas as partes reconhecem que boas relações econômicas possibilitam o alcance de uma paz justa, duradoura e abrangente (PROTOCOLO DE PARIS, 1994, p.

e a Faixa de Gaza, também conhecido como Acordo de Oslo II, que tinha como objetivo central a consolidação de uma entidade auto governável e independente palestina, além da busca pela paz entre os dois lados. 
1). Novamente, a concepção neoliberal de que, apesar da existência de um Sistema Internacional anárquico, duas nações tendem a preferir a cooperação econômica, visto que reconhecem que através desta, é possível alcançar a estabilidade e paz entre as partes.

O Protocolo previa uma grande diversidade de medidas e ações para melhorar a cooperação econômica entre ambas as partes, nos mais diversos setores, como: o estabelecimento do Comitê Econômico Conjunto Palestino-Israelense, que seria responsável pela implementação deste protocolo (Artigo II); uma política de taxas e importação bem estruturada (Artigo III); o estabelecimento da Autoridade Monetária Palestina (AMP), que serviria como uma entidade responsável por orientar a Autoridade Palestina no setor financeiro e econômico (Artigo IV); como deveria funcionar a taxação, tanto direta quanto indireta, por ambas as partes (Artigos V e VI); trabalho, de modo que ambos os lados deveriam tentar manter a normalidade do movimento do trabalho entre eles, sujeito ao direito de cada lado de determinar, de tempos em tempos, a extensão e as condições do movimento operário em sua área, tudo isso sob os cuidados do Comitê Econômico Conjunto (Artigo VII); agropecuária (Artigo VIII); indústrias, de modo que ambos as partes concordaram no livre movimento de bens industriais e que se esforçariam ao máximo para não prejudicar a indústria de ambos os lados (Artigo IX); turismo, de modo que a Autoridade Palestina ficaria responsável por criar uma Autoridade de Turismo Palestino (PROTOCOLO DE PARIS, 1994, p. 2-22).

Todavia, segundo o documento "The Palestinian economy: Macroeconomic and trade policymaking under occupation", elaborado pela Conferência das Nações Unidas sobre Comércio e Desenvolvimento (UNCTAD), em 2012, o Protocolo de Paris não cumpriu exatamente o que propunha. Isso porque, a ANP ficou dependente dos descontos de impostos alfandegários e de importação de Israel, dado que o Estado israelense havia restringido as importações para os TPO de uma maneira particular: as importações eram apenas os bens importados diretamente pelas empresas palestinas por Israel e claramente rotulados como destinados à autorização da ANP. Essas importações, tecnicamente, são tratadas como se fossem produzidas em Israel, de modo que tal tipo de importação representou cerca de $80 \%$ das importações palestinas ${ }^{6}$. Portanto, essa nova relação era assimétrica, os benefícios potenciais desse comércio foram ilusórios e a dependência da economia israelense foi reforçada ao longo dos anos (UNCTAD, 2012, p. 11-12).

Dessa forma, apesar de ser uma relação assimétrica, as trocas comerciais entre as partes foram bem instáveis ao longo dos anos 1990, tendo momentos de aumento e momentos de queda. Um dos mais significativos momentos de queda, principalmente nas exportações palestinas, foi após a Primeira Intifada (1987-1993). Pelo fato das manifestações palestinas terem sido contra a ocupação e opressão promovidas pelo Estado de Israel, o governo israelense, como contramedida, impôs

\footnotetext{
${ }^{6}$ Este documento, elaborado pela ONU, conta com o trabalho de diversos pesquisadores sobre o assunto. Dessa forma, segundo Kanafani (1996), esse tipo de importação foi entre 30 e 40\%, mas, segundo Khalidi (2010), foi cerca de $80 \%$. Optou-se pelo último dado, por ser mais recente.
} 
restrições rígidas de acesso a insumos e mercados, além de requisitos rigorosos de licenciamento e regulamentação (UNCTAD, 2012, p. 12).

Por conseguinte, a implementação desigual e falta de regulamentação adequada do Protocolo de Paris, falharam em criar um quadro geral mais pacífico e equilibrado entre os lados, o que criou exatamente o oposto, ou seja, uma relação desequilibrada entre as partes. Como consequência, a economia palestina encontrou-se presa em uma dependência cada vez mais crescente da economia israelense. Por sua vez, o governo israelense, desde 1994, intensificou os fechamentos e restrições de movimento. Com os acontecimentos da Segunda Intifada (2000-2005)7, essa tendência israelense de intensificar o fechamento econômico e restrições impostas à economia palestina, alcançou seu nível drástico (UNCTAD, 2012, p. 13).

Apesar do Protocolo prever, em seu Artigo IV, que deveria haver a instalação de uma Autoridade Monetária para o povo palestino, Samhouri (2016, p. 585-586) afirma que após a assinatura do Protocolo, os poderes realmente conferidos à AMP eram limitados apenas ao licenciamento e supervisão de bancos comerciais locais. Pelo fato de não haver hoje uma moeda exclusiva dos Territórios Palestinos, a AMP não poderia exercer o papel de política monetária tipicamente desempenhado pelos bancos centrais, nem desempenhar qualquer controle sobre a taxa de câmbio (Ibidem, 2016, p. 585-586).

Ademais, o Protocolo também previa, em seu Artigo II, a criação do Comitê Econômico Conjunto Palestino-Israelense, que deveria funcionar como um órgão responsável por acompanhar a implementação do Protocolo e lidar com problemas relacionados a ele que pudessem surgir ao longo do tempo. Contudo, na prática, o Comitê esteve adormecido durante a maior parte da década de 1990, e, principalmente, durante os anos 2000. O comitê raramente se reunia para discutir as preocupações palestinas e, para o autor, provou ser totalmente ineficaz no cumprimento de seu papel designado (SAMHOURI, 2016, p. 585-586).

Quando partimos para o lado mais técnico, a caracterização do que de fato foi o Protocolo de Paris ainda é confusa. Segundo Kanafani (1996, p. 23), não é possível classificar o Protocolo em nenhuma das formas comuns de integração comercial. Para o autor, apesar do acordo não ser uma união aduaneira no verdadeiro sentido da palavra, o arranjo econômico proposto pelo Protocolo configura-se essencialmente como sendo uma união aduaneira. A possibilidade de haver tarifas externas diferentes para bens e mercadorias específicos é a principal característica que impossibilita o Protocolo de ser efetivamente configurado como uma união aduaneira. Todavia, o Protocolo

\footnotetext{
7 Em 2000, o líder da oposição israelense, Ariel Sharon fez uma visita à Esplanada das Mesquitas, em Jerusalém, todavia, a visita fora interpretada como uma clara e manifesta provocação aos palestinos, que não se conformaram (KURBAN, 2017, p. 51). Além disso, ocorreu ainda o assassinato de manifestantes no local. Os dois fatores combinados foram o suficiente para a deflagração de uma onda de protestos e violência iniciada por jovens palestinos dispostos a lutarem contra o status quo político e econômico nos Territórios Ocupados. Essa manifestação ficou conhecida como Segunda Intifada, que, ao contrário da primeira, teve participação de palestinos residentes em Israel, o que possibilitou o início de confrontos dentro do território israelense (SILVA, 2012, p. 136).
} 
propõe uma estrutura de importações palestinas, de modo que existem três listas (A1, A2, B) que especificam os produtos que podem ser importados pelo lado palestino e de quais países esses produtos seriam exportados. Por conseguinte, a forma que essa estrutura de listas foi elaborada não deixa muito espaço para flexibilidade e manobras, e a política aduaneira palestina é quase idêntica à de Israel. Apesar desta última característica, para o autor, o Protocolo de Paris ainda se configura essencialmente como uma união aduaneira (Ibidem, 1996, p. 23).

Embora próximo em essência a uma união aduaneira, o arranjo proposto também não é muito diferente de um mercado comum, visto que a livre circulação de fatores de produção é o elemento básico que distingue um mercado comum de uma união aduaneira. Ademais, há um movimento de capital quase totalmente livre entre Israel e TPO, visto que o shekel é uma das duas principais moedas em uso nos TPO (sendo a outra o Dinar Jordaniano), e um certo nível de movimento trabalhista para Israel (KANAFANI, 1996, p. 23).

Segundo Arafeh (2018), o Protocolo previa alcançar a formalização das relações econômicas até 1999, todavia, mesmo após sua suposta expiração, o Protocolo continua sendo a base das relações econômicas e é a estrutura para a conduta econômica, monetária e fiscal da ANP. Outro relatório elaborado pela UNCTAD, em 2016, reforça esse posicionamento exposto por Arafeh. Segundo o documento, o Protocolo de Paris não só está expirado desde 1999, em tese, como continua a restringir o espaço político disponível para os formuladores de políticas palestinos, enquanto que reforçam uma quase união aduaneira, como exposto por Kanafani, e asseguram a dependência econômica palestina de Israel (UNCTAD, 2016, p. 8).

Dessa forma, para Arafeh, essa união aduaneira é caracterizada como uma imposição da política comercial de Israel sobre a Cisjordânia e Gaza. Pelo fato de uma união aduaneira não exigir a demarcação ou eliminação de fronteiras, essa estrutura perpassa as questões econômicas e tem interferência direta no âmbito político, visto que possibilita que Israel adie a questão das fronteiras, enquanto promove a contenção e colonização dos TPO (ARAFEH, 2018).

Ademais, Israel comete outra violação do Protocolo, ao determinar que os bens só podem circular livremente de Israel para os TPO, e não vice-versa (medida também adotado durante o período de ocupação de 1967 a 1994), além de restringir o movimento de mercadorias dentro dos TPO. Embora o sistema conceda à ANP acesso a recursos significativos, ele também concede a Israel poder sobre a receita palestina, que explora esse controle retendo as receitas tributárias como uma medida punitiva ou para exercer pressão política para com a população palestina (ARAFEH, 2018).

Dado o exposto, observa-se que durante o período de 1967 a 1994, o Estado de Israel impôs uma série de medidas restritivas ao povo palestino, de modo a impedir o desenvolvimento sócioeconômico e reforçar uma estrutura de dependência para com Israel. Dessa forma, com a assinatura do Protocolo de Paris, em 1994, ambos os lados pretendiam construir uma melhor relação econômica que fosse capaz de perpassar o âmbito econômico e impactar, também, o âmbito político com o intuito de trazer a estabilidade e paz entre as partes. Assim, o lado palestino, em específico, tinha 
como objetivo principal romper com essa estrutura de dependência e experienciar um desenvolvimento econômico independente após o período de cinco anos, como propunha o Protocolo. Todavia, nota-se que o Protocolo não só não foi capaz de garantir o desenvolvimento de uma estrutura econômica palestina independente, dentro do período estipulado, como também não foi capaz de romper com essa estrutura de dependência econômica vigente há décadas.

\section{CONSIDERAÇÕES FINAIS}

O presente trabalho buscou compreender se o Protocolo de Paris de 1994, o mais importante acordo econômico firmado entre Israel e OLP, acarretou em ganhos absolutos significativos entre as partes, à luz do neoliberalismo institucional.

Para tanto, no primeiro tópico se fez a exposição da fundamentação teórica aqui utilizada. Assim, o trabalho optou pelo uso do neoliberalismo institucional, visto que tal abordagem possui uma visão mais positiva sobre a cooperação internacional e o setor econômico. De modo mais específico, o trabalho fez uso de trabalhos neoliberais direcionados para a cooperação entre nações em conflito e/ou nações inimigas, como os trabalhos de Liberman (1996) e Barnathan (2006). Para estes autores, a estabilidade econômica pode impactar no bem-estar social e segurança de um Estado e vice versa. Dessa forma, a cooperação econômica representa um momento inicial de uma futura cooperação nos mais altos e amplos níveis dos problemas políticos e de segurança, visto que a integração econômica pode trazer paz e/ou ajudar a atualizar a paz propriamente dita.

Ao que tange o contexto palestino-israelense, esse tipo de abordagem é capaz de explicar inicialmente o Protocolo de Paris (1994) - o mais importante acordo econômico assinado entre as partes - visto que representa um cenário em que ambos os lados se propuseram a desenvolver uma cooperação econômica, mesmo inseridos em um longo conflito histórico. Já no tópico seguinte, fezse uma exposição e problematização do Protocolo de Paris em si. Contudo, antes de entrar especificamente na discussão sobre o Protocolo, houve a exposição do histórico comercial entre Israel e TPO de 1967 a 1993.

Antes de apresentar as considerações finais sobre a análise do Protocolo, é válido destacar aqui a lógica dos três níveis gradativos de paz de Miller (2005). Em seu trabalho, o autor nos apresenta os conceitos dos três níveis de paz e como eles relacionam-se entre si, apresenta também um cenário em que o conflito palestino-israelense não só pode ser superado, como se pode alcançar o terceiro nível de paz, a calorosa. Contudo, uma das questões chaves para que essa paz calorosa seja alcançada, é a interferência estadunidense. Como evidenciado no fracasso dos Acordos de Oslo, a mediação estadunidense não é a solução. Ademais, sua proposição é falha ao não levar em consideração duas questões fundamentais: o alto nível de dependência palestina para com Israel, e; o fato de Israel ser um importante aliado dos Estados Unidos na região o que, consequentemente, 
seria o suficiente para enviesar a cooperação entre as partes e, possivelmente, estruturar este acordo de paz hipotético de acordo com interesses israelenses.

Quando analisamos o Protocolo, podemos perceber que o mesmo propunha uma cooperação simétrica e equilibrada, em que ambos os lados saíssem ganhando, a paz fosse alcançada e uma Autoridade Monetária fosse instaurada com o objetivo de funcionar como um órgão orientador oficial de questões econômicas e financeiras do povo palestino. Quando relacionamos tal acordo com o neoliberalismo, apesar dessa abordagem ser capaz de explicar, na teoria, como o acordo representa um maior estreitamento econômico, mesmo em um cenário conflituoso, uma análise mais aprofundada da implementação e efeitos pós-Protocolo, mostram uma situação mais complicada.

O que fica evidente é que, mesmo antes do acordo, havia uma relação de dependência do lado palestino para com o lado israelense, como observado nas relações econômicas entre as partes, de 1967 a 1993. Um dos principais objetivos deste Protocolo, em tese, seria o desenvolvimento econômico palestino, ao ponto de quebrar com essa dependência para com Israel. Todavia, o acordo não cumpriu esse objetivo e a realidade manteve-se da mesma forma que o período histórico préProtocolo, pois os palestinos continuaram a depender do controle e autorização israelense para muita coisa.

Como exposto anteriormente por Barnathan (2006), a divergência de poderes em uma relação econômica gera três problemas inter-relacionados, mas diferentes: o problema do poder coercivo; o problema do efeito de influência; o problema em concordar com o significado da cooperação mútua. Ao relacionar tais problemas com o contexto que envolve o Protocolo de Paris, é possível identificar principalmente o primeiro dos três problemas, visto que, pelo fato de Israel ser um Estado com maior poder econômico e político, beneficia-se diretamente com o Protocolo e ainda é capaz de impor poder coercitivo sobre os TPO.

Pelo fato do Protocolo ter sido firmado dentro do âmbito da ONU, serviu como um mecanismo utilizado por Israel, para alcançar determinados objetivos. Entre eles, a promoção da imagem do Estado de Israel, para os outros Estados do Sistema Internacional, como um Estado democrático, aberto ao diálogo e cooperação com o outro lado, muitas vezes considerado inimigo e violento. Outro objetivo específico, foi que, ao propor uma estrutura econômica semelhante a uma união aduaneira, que não exige delimitação de fronteiras geográficas, o Estado de Israel utiliza-se do Protocolo como uma espécie de justificativa para a colonização e ocupação indevida de territórios.

Ademais, apesar do Protocolo de Paris promover a "cooperação entre os dois lados", em nenhum momento aparece o termo “cooperação internacional”. Isto porque não há o reconhecimento dos TPO como um Estado reconhecido plenamente, contrariando o documento, também assinado no âmbito da ONU, de 1948. Isto leva a outra problemática: como afirma Kanafani (1996), não há fronteiras alfandegárias entre Israel e TPO e a principal moeda em circulação nos TPO é o shekel israelense. Além de possibilitar que exista uma união aduaneira entre os lados, a 
problemática real está no fato de que tais fatores indicam o óbvio: o Estado de Israel não só tem ocupado geograficamente os territórios palestinos, mas há, também, uma "ocupação econômica".

Após o exposto, é necessário retomar a pergunta inicial: é possível haver uma cooperação econômica, com ganhos absolutos significativos, entre duas nações em conflito? Segundo uma perspectiva neoliberal institucional, toda cooperação econômica apresenta ganhos absolutos, que mesmo que desiguais ainda assim são melhores do que buscar tais ganhos de maneira independente. Todavia, a assinatura de um acordo econômico entre duas nações em conflito histórico é muito mais complexa e profunda. No caso palestino-israelense, mais especificamente, o Protocolo de Paris não apresentou ganhos absolutos tão benéficos para o lado palestino. Pelo contrário, segundo autores como Kanafani (1996) e Arafeh (2018), o Protocolo serviu (e continua servindo) como um mecanismo de formalização do controle de Israel sobre a economia palestina, o que, como resultado, perpetuou a dependência econômica palestina para com Israel. Dessa forma, uma melhor resposta para a pergunta acima seria que, nem toda cooperação econômica apresenta ganhos absolutos significativos ao ponto de perpassar as problemáticas sócio-políticas existentes em um cenário de conflito histórico.

*Artigo recebido em 20 de abril de 2020, aprovado em 22 de agosto de 2020.

\section{REFERÊNCIAS}

ARAFEH, Nur. Long Overdue: Alternatives to the Paris Protocol. alShabaka: The palestinian policy network. 2018. Disponível em: <https://al-shabaka.org/summaries/long-overduealternatives-paris-protocol/>. Acesso em: 03/09/2020.

AXELROD, Robert; KEOHANE, Robert. Achieving Cooperation under Anarchy: Strategies and Institutions. World Politics, Vol. 38, No. 1, 1985, pp. 226-254.

BARBIERI, Katherine; LEVY, Jack S. Sleeping with the Enemy: The Impact of War on Trade. Journal of Peace Research, vol. 36, No. 4, 1999, p. 463-479.

BARNATHAN, Galia. The Neglected Dimension of Commercial Liberalism: Economic Cooperation and Transition to Peace. Journal of Peace Research, Vol. 43, No. 3, 2006, pp. 261-278.

B'TSELEM. The Palestinian economy: 1967-1994. 2011. Disponível em: <https://www.btselem.org/freedom of movement/economy 1967 1994>. Acesso em: 03/09/2020.

GOMES, Aura Rejane. A questão da Palestina e a fundação de Israel. Dissertação (Mestrado em Ciência Política) - Departamento de Ciência Política, Universidade de São Paulo. São Paulo, 2001. Disponível em: $\quad$ https://www.teses.usp.br/teses/disponiveis/8/8131/tde-24052002163759/publico/TeseAuraGomes.pdf > . Acesso em: 03/09/2020. 
GRESH, Alain. Israel, Palestina: Verdades sobre um Conflito. Editora Campo das Letras, 1a ed., 2002.

GRIECO, Joseph. Anarchy and the limits of cooperation: a realist critique of the newest liberal institutionalism. International Organization, 42, 3, 1988.

KANAFANI, Nu'man. Trade Relations Between Palestine and Israel: Free Trade Area or Customs Union? Palestine Economic Policy Research Institute (MAS). 1996. Disponível em: $<$ https://www.academia.edu/9069068/Trade Relations between Israel and PalestineCustoms Union verses Free Trade Area $>$. Acesso em: 03/09/2020.

KURBAN, Thiago Müller. Organizações Internacionais de Direitos Humanos: a atuação da anistia internacional e da Human Rights Watch na ofensiva israelense chumbo fundido. Porto Alegre. Dissertação (Mestrado em Ciências Sociais) - Escola de Humanidades, Pontifícia Universidade Católica do Rio Grande do Sul, 2017. Disponível em: < http://tede2.pucrs.br/tede2/bitstream/tede/7455/2/DIS THIAGO MULLER KURBAN COM PLETO.pdf $>$. Acesso em: 03/09/2020.

LIBERMAN, Peter. Trading with the Enemy: Security and Relative Economic Gains. International Security, Vol. 21, No. 1, 1996, p. 147-175.

LOPES, Liana Araujo. A Autoridade Palestina e a resolução do conflito em Israel. Tese (Doutorado em Relações Internacionais) - Pontifícia Universidade Católica do Rio de Janeiro, 2007. Disponível em: < https://doi.org/10.17771/PUCRio.acad.9544> . Acesso em: 03/09/2020.

MILLER, Benjamin. When and How Regions Become Peaceful: Potential Theoretical Pathways to Peace. International Studies Review, vol. 7, No. 2, 2005, p. 229-267.

ONU. Declaration of Principles on Interim Self-Government Arrangements. 1993. Disponível em: <https://peacemaker.un.org/sites/peacemaker.un.org/files/IL\%20PS 930913 DeclarationPrinci plesnterimSelf-Government\%280slo\%20Accords\%29.pdf > . Acesso em: 03/09/2020.

ONU. Protocol on Economic Relations between the Government of the State of Israel and the P.L.O. $\quad 1994$ Disponível <https://unctad.org/Sections/gds appu/docs/ParisProtocol en.pdf $>$. Acesso em: 03/o9/2020.

OYE, Kenneth. Explaining Cooperation under Anarchy: Hypotheses and Strategies. World Politics, Vol. 38, No. 1, 1985, pp. 1-24.

PACTO da Sociedade das Nações, 1919. Disponível em: <https://bit.ly/2QRTwUP>. Acesso em: 03/09/2020.

PILATI, Anselmo; PIRES, Ariel. O Conflito Palestino-Israelense e o Oriente Médio. 2008. Disponível em: <http://www.diaadiaeducacao.pr.gov.br/portals/pde/arquivos/710-4.pdf $>$. Acesso em: 03/09/2020.

SAMHOURI, Mohammed. Revisiting the Paris Protocol: Israeli-Palestinian Economic Relations (1994-2014). The Middle East Journal, Vol. 30, No. 4, 2016.

SILVA, Ana Paula Maielo. A política palestina: construção, dinâmicas e desdobramentos. Campinas. Tese (Doutorado)- Instituto de Filosofia e Ciências Humanas, Universidade Estadual de Campinas, 2012. Disponível em: <http://repositorio.unicamp.br/jspui/bitstream/REPOSIP/280943/1/Silva AnaPaulaMaielo D.p df $>$. Acesso em: 03/09/2020. 
SOARES, Jurandir. Israel x Palestina: As Raízes do Ódio. Porto Alegre: Editora da Universidade/UFRGS, 1989.

UNCTAD. The Palestinian economy: Macroeconomic and trade policymaking under occupation. Genebra, $2012 . \quad$ Disponível em: <https://unctad.org/en/PublicationsLibrary/gdsapp2011d1 en.pdf $>$. Acesso em: 03/09/2020.

UNCTAD. Report on UNCTAD assistance to the Palestinian people: Developments in the economy of the Occupied Palestinian Territory. 2016. Disponível em: <https://unctad.org/en/PublicationsLibrary/app2016d1 en.pdf > . Acesso em: 03/o9/2020. 